\title{
Capsule retention in a giant Meckel's diverticulum containing multiple enteroliths
}

A 58-year-old man presented to hospital with diffuse abdominal pain, melena, and iron-deficiency anemia. Gastroscopy and colonoscopy were unremarkable. Wireless capsule endoscopy (WCE) (PillCam SB2; Given Imaging, Yoqneam, Israel) was then carried out. The video sequence showed the capsule passing through a narrow orifice of the distal ileum into a cavity containing multiple enteroliths swirling in a greenish fluid with debris ( $\bullet$ Figs. 1 and 2). Small ulcers were also demonstrated near the orifice in the bowel lumen. The capsule remained within the cavity until the battery was exhausted.

Consequently, computed tomography (CT) demonstrated a dilated part of the bowel at the right abdomen, filled with enteral contrast and containing a hyperdense foreign body - corresponding to the capsule - and multiple ovoid structures, each with a thick rim of intermediate density and low-density center $($ Fig. 3).

The patient was operated on, and a giant enteral diverticulum ( $\bullet$ Fig. 4) containing the capsule and four enteroliths was found ( Fig. 5).

Histological examination proved this to be a Meckel's diverticulum with few small ulcers, without the presence of ectopic gastric mucosa.

Obscure gastrointestinal bleeding is the most common indication for WCE, yielding high detection and low retention rates [1]. Crohn's disease, neoplasia, abdominal radiation injury, prolonged nonsteroidal anti-inflammatory drug use, and previous major abdominal surgery or small-bowel resection are the most common reasons for capsule retention [1]. There are few reported cases of capsule retention in a small-bowel diverticulum, either a simple diverticulum or Meckel's diverticulum [2-4]. Meckel's diverticula that do not have gastric mucosa - like in our case create a more alkaline environment, promoting precipitation of calcium and other minerals essential for enterolith formation [5]. It has been reported that only $10 \%$ of Meckel's diverticula contain enteroliths [5].

To our knowledge, this is the first report of WCE providing images of a Meckel's diverticulum containing enteroliths.

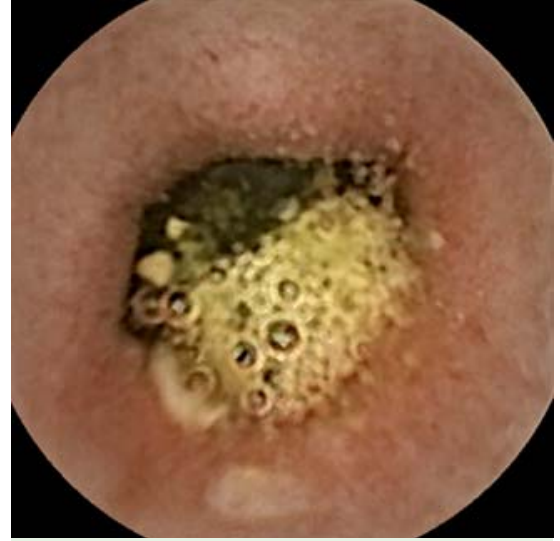

Fig. 1 Wireless capsule endoscopy (WCE) showing the narrow orifice in the distal ileum which leads to a cavity (the greenish structure behind) containing enteroliths.

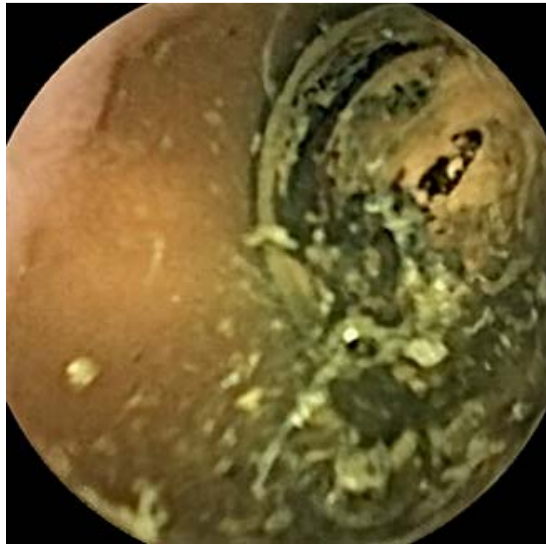

Fig. 2 Wireless capsule endoscopy (WCE) image of an enterolith inside the Meckel's diverticulum.

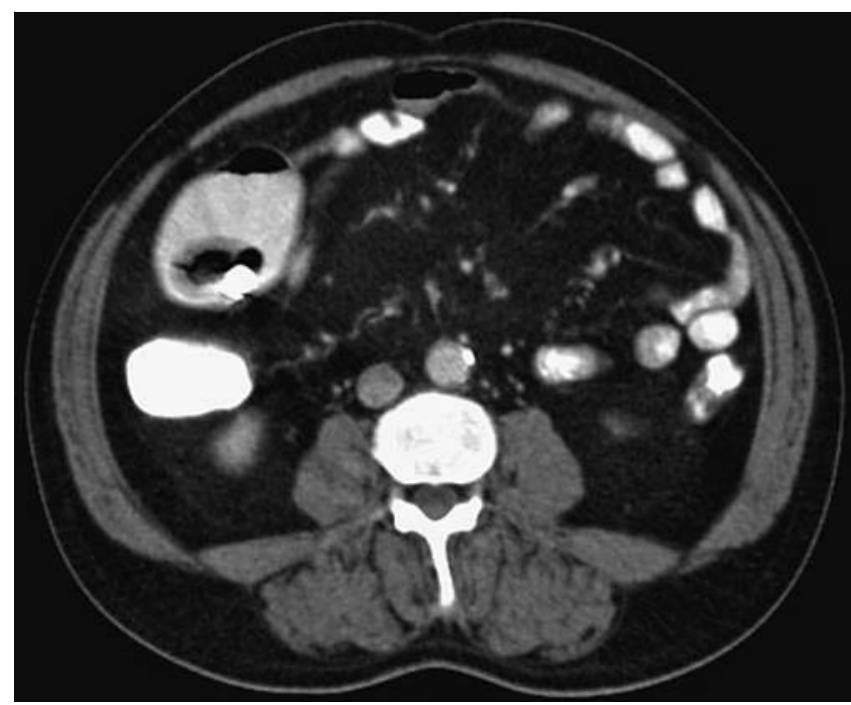

Fig. 3 Computed tomography (CT) image demonstrating a dilated part of the bowel, filled with the enteral contrast (given orally), and containing the capsule and multiple enteroliths, each with a thick rim of intermediate density and low-density center.

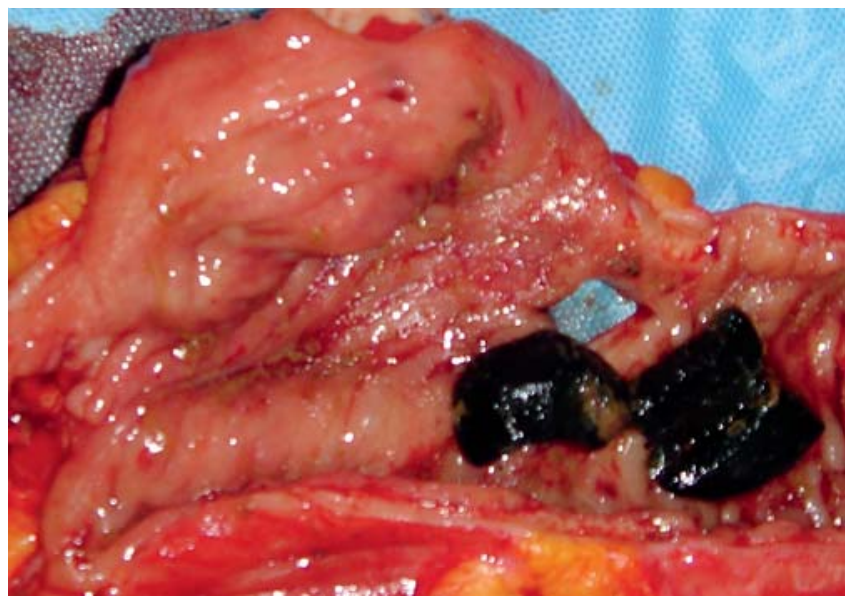

Fig. 4 Gross specimen of the Meckel's diverticulum. Some of the enteroliths are shown. 


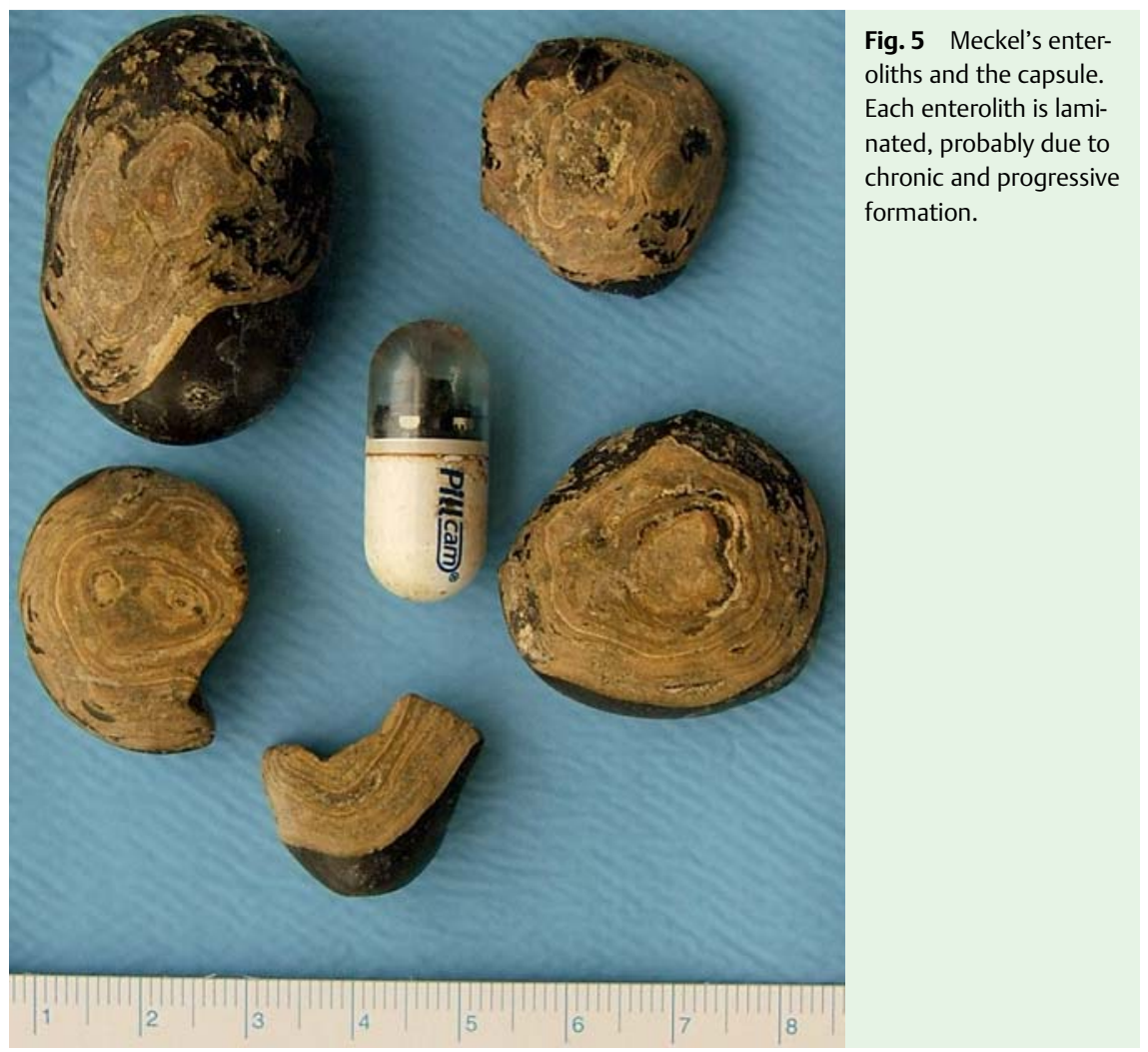

Endoscopy_UCTN_Code_CPL_1AI_2AB

Competing interests: None
N. Courcoutsakis ${ }^{1}$, M. Pitiakoudis ${ }^{2}$, K. Mimidis ${ }^{3}$, S. Vradelis ${ }^{3}$, E. Astrinakis ${ }^{1}$, P. Prassopoulos ${ }^{1}$

1 Department of Radiology and Medical Imaging, Democritus University of Thrace, Alexandroupolis, Greece

2 2nd Department of Surgery, Democritus University of Thrace, Alexandroupolis, Greece

3 Endoscopic Unit, 1st Department of Internal Medicine, Democritus University of Thrace, Alexandroupolis, Greece

\section{References}

1 Liao Z, Gao R, Xu C, Li ZS. Indications and detection, completion, and retention rates of small-bowel capsule endoscopy: a systematic review. Gastrointest Endosc 2010; 71: 280-286

2 Giday SA, Pickett-Blakely OE, Buscaglia JM, Mullin GE. Capsule retention in a patient with small-bowel diverticulosis. Gastrointest Endosc 2009; 69: 384 - 386

3 Tanaka Y, Motomura Y, Akahoshi Ket al. Capsule endoscopic detection of bleeding Meckel's diverticulum, with capsule retention in the diverticulum. Endoscopy 2010; 42: 199-200

4 Ordubadi P, Blaha B, Schmid A et al. Capsule endoscopy with retention of the capsule in a duodenal diverticulum. Endoscopy 2008; 40: $247-248$

5 Pantongrag-Brown L, Levine MS, Buetow PC et al. Meckel's enteroliths: clinical, radiologic, and pathologic findings. Am J Roentgenol 1996 Dec; 167: 1447 - 1450

\section{Bibliography}

DOI $10.1055 / \mathrm{s}-0030-1256641$

Endoscopy 2011; 43: E308 -E309

(c) Georg Thieme Verlag KG Stuttgart · New York . ISSN 0013-726X

\section{Corresponding author}

\section{N. Courcoutsakis, MD D(Med)Sci}

Department of Radiology and Medical Imaging University Hospital of Alexandroupolis 68100 Alexandroupolis

Greece

Fax: +30-255-1030312

ncourcou@med.duth.gr 